\title{
EN BUSCA DEL REINO PERDIDO \\ (PARA UNA POÉTICA DEL CUENTO EN JULIO GARMENDIA)
}

POR

\author{
Óscar Sambrano Urdaneta
}

Julio Garmendia fue siempre esquivo a las entrevistas periodísticas; pero las pocas que concedió están llenas de parcas y sustanciosas consideraciones sobre la literatura en relación con la vida, así como también acerca de su peculiar concepto de sí mismo como narrador. Una de esas entrevistas, excelente y excepcional desde muchos puntos de vista, es la que le hizo Teresa Alvarenga con motivo de haber ganado en julio de 1973 el Premio Nacional de Literatura, esto es, a escasos años de su gravedad y muerte. Las ideas fundamentales que allí manifestó a la periodista tienen, por de pronto, la importancia de coronar una larga existencia de trabajo intelectual continuo. Constituyen, pues, un auténtico desiderátum. Creo no equivocarme si sustento el criterio de que en dichas declaraciones se encuentran las dos ideas directrices fundamentales de su concepción del relato, $o$, si se prefiere, de su poética. Estas ideas rectoras se hallan contenidas en los siguientes párrafos:

Periodista: A usted siempre se le ve como un escritor aislado, solo, que no pertenece al mundo en el que uno se desenvuelve todos los días, a quien uno apenas se atreve a acercarse y me decía que es tal vez porque usted no está totalmente aquí.

Julio Garmendia: Sí hay algo de eso; pero no es eso al mismo tiempo. Es difícil de explicar. Creo que fundamentalmente viene de la forma de mi espíritu, alejado de ruidos y de figuraciones. Yo tiendo a evitarlo, no por rechazo, sino porque es algo inherente a mi persona. En Europa me comportaba hasta peor, puesto que allá tenía menos conocidos.

Periodista: ¿Es usted un hombre solo o más bien prefiere la soledad?

Julio Garmendia: Yo amo la soledad. Encuentro una afinidad con ella. La soledad a mi manera de ver es importante y la base para muchas cosas, sobre todo me refiero a los escritores.

Periodista: Algunos críticos juzgan que usted es un escritor que se anticipó a su época, ¿qué le parece esta afirmación?

Julio Garmendia: Esa afirmación es extraña a mí, no la siento así, siempre he vivido en un mundo un poco aparte en el cual lo que escribo es perfectamente corriente. Esa idea de exterior a mí, no me toca de ninguna manera.

Periodista: ¿Cómo es ese mundo donde usted habita?

Julio Garmendia: Un lugar de fantasía alejado de la vida social y literaria, donde habitan pájaros, naturaleza, paisaje y en este momento Teresa Alvarenga. 
Periodista: (Cuando le digo que al releer varios relatos antes de la entrevista encontré una extraña mezcla de realismo y cosas insólitas y su enorme interés por los detalles, Julio Garmendia afirma que es un gran observador).

Julio Garmendia: En parte soy un escritor realista y en parte un fantaseador, aspectos que se contraponen al principio, pero que se amalgaman al mismo tiempo en la vida y en la obra. ${ }^{1}$

En esta entrevista hay algunas expresiones capitales dichas por Garmenida en respuesta a las preguntas de la periodista. La primera de estas expresiones conduce a un hecho que el cuentista considera corriente, pero que es, en verdad, extraordinario. "Siempre he vivido en un mundo un poco aparte en el cual lo que escribo es perfectamente corriente". ¿Qué se desprende de esta confesión? Siempre he vivido da la idea de algo consubstancial con la persona, que abarca, por tanto, la totalidad de su existencia. No se trata de períodos de aislamiento que alternana con otros de sociabilidad, sino de un estilo de vida, más o menos invariable, sostenido a lo largo de los años. Siempre he vivido ... en un mundo un poco aparte. Este segundo aspecto se presta a una doble interpretación. Un mundo aparte puede significar aislamiento físico, soledad, forma de vida propia que lo aleja de los demás; pero puede aludir, también, a un mundo interior, íntimo, poblado de visiones, rico en presencias nada comunes. Se trata del universo prodigioso de la memoria, de la fantasía creadora, de la inteligencia; un orbe íntimo del cual el propio Julio Garmendia pudo decir que "uno dentro de sí mismo encuentra las cosas". ${ }^{2}$ Estas "cosas" vienen del mundo exterior y constituyen el granero de imágenes y de ideas atesorado por un gran observador que sabe ver para poder contar, según frase exacta que recuerdo haberle oído a Gustavo Díaz Solís. Pero esas "cosas", una vez incorporadas al universo interior del cuentista, dejan de ser parte de la realidad cotidiana porque se han interiorizado y obedecen a leyes diferentes, como son las que gobiernan el acto creador. Es admisible que en ese mundo aparte, un lugar de fantasía alejado de la vida social y literaria, Julio Garmendia haya juzgado lo que escribe como perfectamente corriente, ya que su acto creador se inscribe en ese ámbito de elementos reales y elementos fantásticos que conviven en perfecto equilibrio y armonía. De ahí su aseveración, en parte soy un escritor realista y en parte soy un fantaseador, sintetiza, en definitiva, su postura como narrador de grandes alcances. Así lo corrobora el otro documento fundamental para cualquier aproximación a la poética de Julio Garmendia. Es un relato, "El cuento ficticio", perteneciente al volumen La tienda de muñecos. A diferencia de las declaraciones para Teresa Alvarenga, relativamente recientes, esta página se sitúa entre sus más lejanos textos. Podría fecharse a comienzos de la década de los años veinte. $Y$ esto tiene importancia.

¿Cuáles son los planteamientos que Garmendia hace en este relato? En una atmósfera de humor, ligeramente tocada de ironía, su primer planteamiento se refiere a la bonanza que en un tiempo vago, indefinido, tuvieron los "héroes de historias", los cuales eran todos "perfectos y felices al extremo de ser completamente inverosímiles". A aquellos héroes idealizados, que recuerdan a los más característicos personajes de la épica y a los famosos

${ }^{1}$ Teresa Alvarenga, entrevista a Julio Garmendia. Diario El Nacional (Caracas, 8 de marzo de 1974). Arte, C-13.

${ }^{2}$ Expresión textual, extraída de la grabación de la entrevista hecha por Teresa Alvarenga. 
caballeros andantes, a los pobres diablos de la picaresca y, más recientemente, todo el inagotable desfile de tipos y personajes de la novela realista y naturalista. Así, pues, de la perfección paradigmática de los antiguos señores del relato, los protagonistas de ahora degeneraron hasta llegar a ser "los descompuestos sujetos que ahora somos, que hemos dado en el absurdo de no ser absolutamente ficticios, y de extraordinarios y sobrenaturales que éramos nos hemos vuelto verosímiles, y aun verídicos, y hasta reales". Señalo de paso la importancia que tiene para la mejor comprensión del relato de Julio Garmendia la oposición que se da entre lo extraordinario/sobrenatural y lo verosímil/verídico/real. Ante esta oposición, y como si se tratara de una primera conclusión exclama: “¡Extravagancia! ¡Aberración! ¡Como si fuéramos otra cosa que ficticios que pretendemos dejar de serlo! ¡Como si fuera posible impedir que sigamos siendo ilusorios, fantásticos e irreales aquellos a quienes se nos dio, en nuestro comienzo u origen, una invisible y tenaz torcedura en tal sentido!" Por tanto, dada la antinomia que suponía la presencia de personajes irreales en una tradición que imponía al realismo y al naturalismo como las corrientes deseables, y habida cuenta del dudoso gusto literario que había convertido en héroes a los personajes de los folletines detectivescos, el personaje-narrador de "El cuento ficticio", entre veras y chanzas se erige en líder y representante "de los inverosímiles héroes de Cuentos Azules de que ya no se habla en las historias" y asegura que su ideal es nada menos que "restaurar nuestras primeras perfecciones, bellezas e idealismos hoy perdidos ... regresar todos ... a los Reinos y Reinados del país del Cuento Azul, clima feliz de los irreal, benigna latitud de lo ilusorio". Para concluir su elocuente discurso, el personaje-narrador hace así el elogio de su proyecto: "Aventura verdaderamente imaginaria, positivamente fantástica y materialmente ficticia de que somos dignos y capaces los que no nacimos sujetos a aventuras policiales de continuación o a falsos héroes de folletines detectivescos".

Quien lleva la palabra en el cuento decide entonces comunicarle al lector cuáles van a ser los pasos que él dará para que se verifique tan extraordinaria aventura. La primera de tales providencias consisten en reunir toda la documentación que precisa la existencia y situación del país del Cuento inverosímil. Esto con el objeto de salirles al paso a quienes se empecinaban en demostrar lo contrario, "como si hubiera algún mérito en no creer en los Cuentos fabulosos, en tanto que lo hay muy cierto en saber que sí existieron". Por supuesto que, en algún momento, el personaje adquiere conciencia de que es un innovador, y de que, como tal, está expuesto a que lo llamen "loco, inexperto, utopista" aquéllos que oponen a sus puntos de vista "grandes personajes voluminosos; o sea los que en gruesos volúmenes se arrellanan cómodamente y a sus anchas respiran en un ambiente realista" o la de los personajes de novela, novelón o novelín, que pretenden ser superiores en rango y calidad "a quienes en las lindes del Cuento hemos nacido".

El personaje del "Cuento ficticio" continúa expresando su fe en el mejoramiento de la "especie" ficticia y alegando que su "incurable idealismo" lo "incita a laborar sin reposo en esta temeraria empresa; y a la larga acabaré por probar la existencia del país del Cuento Improbable a estos mismos ficticios que hoy la niegan, y hacen burla de mi fe, y se dicen sagaces sólo porque ellos no creen, en tanto que yo creo". Concluye aludiendo al Cuento ilusorio, a la búsqueda del Reino Perdido, aseverando que existe el Cuento irreal y apoyándose en "la fe que tengo y me ilumina en su final descubrimiento y posesión". 
Ya viejo, el personaje garmendiano (como su verdadero padre literario lo hizo) les mostrará a sus seguidores la fantástica visión de las montañas de los Cuentos Azules.

Un examen detenido de este relato-manifiesto, que ponga de lado la retórica intencional del humorista, encontrará en él las llaves del Reino Perdido, esto es, de la poética que sirvió de base y de inspiración a casi toda la obra narrativa de Julio Garmendia. Basta, por ahora, una frase para comenzar a darnos cuenta de cuáles fueron las innovaciones que este creador introdujo en el cuento, y que lo convirtieron en un adelantado a su tiempo. La frase es ésta: nuestro exilio en lo Real. Quien la dice es el personaje líder de "El cuento ficticio" expresándose en nombre de todos los que como él, siendo por verdadera y consubstancial naturaleza perfectamente ficticios, han tenido que comparecer ante un mundo que los toma y los desea como si fueran reales. Si no me equivoco, hay todo un planteamiento de fondo en esta sencilla frase, sencilla en apariencia. No se trata, como pudiera parecer lo normal, de personajes reales que se tornan inverosímiles, ni de personajes ficticios que desean que se les considere como reales, sino de personajes ficticios que reclaman su derecho a seguir siendo ilusorios, fantásticos e irreales; y, que piden, por lo tanto, que se les deje vivir en los Reinos y Reinados del país del Cuento Azul, esto es, libres de las ataduras de la lógica realista, cotidiana, en una dimensión de libertad absoluta, donde podrían obrar sin restricción alguna. Esta es, a mi juicio, la revolución que Julio Garmendia propone con su avanzada narrativa. Nadie en Venezuela, y, seguramente, nadie tampoco en la América Hispana, estaba pensando y escribiendo bajo el dictado de estas novedosas ideas, que venían a resucitar, a la manera de este creador, el espíritu de los hechos extraordinarios de aquel tiempo ya sin tiempo en que los héroes de historias eran todos perfectos y felices. Su ideal, dicho por boca de su personaje, fue nada menos que "restaurar nuestras primeras perfecciones, bellezas e idealismos hoy perdidos: regresar todos - héroes y heroínas, protagonistas y personajes, figuras centrales y figurantes episódicos - regresar, digo, todos los ficticios que vivimos, a los Reinos y Reinados del país del Cuento Azul, clima feliz de lo irreal, benigna latitud de lo ilusorio". Es ésta la definición que el propio Garmendia nos da del Cuento azul, denominación que a juicio de uno de sus críticos más minuciosos, Julio Barroeta Lara, pudiera haber sido tomada del libro primigenio de Rubén Darío, quien había llegado a afirmar que el azul era el color del ensueño y del arte. ${ }^{3}$

Dentro de esta denominación de Cuentos azules, Julio Garmendia agrupa con mucha originalidad, las siguientes categorías de relatos breves: El Cuento inverosímil, que es aquél que carece de apariencia de verdad. También lo denomina Cuento fabuloso, adjetivo que se define, según el Diccionario de Autoridades, como "mentiroso, incierto, y que contiene en sí fábula o ficción". Esta categoría de cuento inverosímil o fabuloso la opone Garmendia al realismo grosero de las historias que disponen de "grandes personajes voluminosos; o sea los que en gruesos volúmenes se arellanan cómodamente y a sus anchas respiran en un ambiente realista". Todavía señala tres categorías más, que podrían ser puramente nominales, esto es, que sólo establecen una diferencia de nombre con las dos

\footnotetext{
${ }^{3}$ Julio Barroeta Lara, "No importa no llegar a ninguna parte", Viaje al interior de un cofre de cuentos (Julio Garmendia entre líneas) volumen 26 (Caracas: Academia Nacional de la Historia, El Libro Menor, 1982).
} 
primeramente mencionadas. Son ellas: el Cuento improbable, el Cuento ilusorio y el Cuento irreal. Una mirada atenta a estas cuestiones pone de relieve el sutil y sabio empleo de las palabras que, por lo demás y desde entonces, se constituyó en una de las características más acusadas y notables de la prosa de este narrador. No podrían considerarse como sinónimos "improbable" e "ilusorio", en tanto que "irreal" podría admitirse sin esfuerzo como próximo a los significados de "inverosímil" y de "fabuloso". En cualquier caso, con matices de significación o sin ellos, estos puntos de vista de Julio Garmendia conducen a la resurrección de aquellos elementos narrativos extraordinarios - personajes, situaciones, ambientes- que este narrador sitúa como propios del País de los Cuentos Azules, título que debiera tomarse en cuenta a la hora de una edición de sus obras completas. Finalmente, si bien es cierto que todas estas denominaciones -inverosímil, fabuloso, improbable, ilusorio, irreal- sólo pueden definirse por oposición a lo real, a lo verdadero, a lo verosímil, a lo probable, no menos cierto es que Garmendia, en uno de sus "Aforismos" todavía inéditos, de 1925, sintetizó estas ideas, que bien pudieran considerase como básicas en su concepción del relato, y como genial anticipo a toda la teoría esencial que luego se inscribió dentro de la denominación realismo mágico:

La característica de nuestro mundo es que aquí todo puede tener visos de verdad, de veracidad o de verosimilitud. De ahí la mentira que no es más que una verdad aplicada a un objeto que no es el suyo. ${ }^{4}$

Quedarían incompletas estas apreciaciones acerca de la concepción que Julio Garmendia tuvo del cuento si no se hiciesen algunas consideraciones sobre su condición de humorista.

El humor, como la poesía, es indefinible, y sólo se conoce por su concreción particular en gestos y situaciones - Chaplin, Cantinflas - por su expresión a través de textos en prosa y en verso - Job Pim, Aquiles Nazoa, Miguel Otero Silva, Julio Garmendia- o de dibujos y caricaturas - Leo, Zapata, Quino. Se saben, en cambio, algunas cosas. La verdadera y única fuente del humorismo es la vida misma. Sin ella, no habría humoristas, como no habría tampoco ninguna otra manifestación del intelecto. Pero descubrir y saber expresar el sentido humorístico de la vida requiere de una conformación anímica especial. Si fuera a trazarse el retrato de un humorista a partir de algunas de las definiciones que se han dado de él, habría que concebirlo, sin duda, como un espíritu superior, reflexivo, escéptico, capaz de divertirse aun con aquello que lo entristece (Ritcher); dotado de cierta agria disposición para descubrir y expresar lo ridículo de lo serio y lo serio de lo ridículo (Bonghi). El humorista supone, además, la actividad de una inteligencia minuciosa y maliciosamente analítica (Lipps). ${ }^{5}$ Otros señalan que el humorista auténtico "ha de ser bondadoso y un poco paternal. Sin actitud, porque comprende, y sin crueldad, porque uno

\footnotetext{
${ }^{4}$ De un original manuscrito de puño y letra de Julio Garmendia, perteneciente al Archivo de César Zumeta, hoy bajo custodia de La Casa de Bello. La carta con la cual le acompaña Garmendia a Zérega Fombona trece páginas de "aforismos" está fechada en París el 25 de mayo de 1925.

${ }^{5}$ Luigi Pirandello: Esencia, caracteres y materia del humorismo (Madrid: Ediciones Guadarrama, 1968).
} 
de sus componentes es la ternura" (Fernández Flórez). ${ }^{6}$ En un trabajo especializado sobre este asunto, no sería difícil continuar transcribiendo las opiniones numerosas dadas sobre el humor, el humorismo y los humoristas. Pero se trataría de un camino largo, que probablemente no conduciría a ninguna parte, pues, como lo señala Luigi Pirandello, ${ }^{7}$ el humorismo tiene tan infinitas variedades y características tan abundantes que, si se parte de éstas, tomando a algunas de ellas como esenciales, se corre el riesgo inevitable de llegar a tener tantas definiciones como características encontradas. Por tanto, concluye Pirandello, "la misión de la crítica es estudiar el contenido y el tono de cada humor; es decir, la personalidad de cada humorista", porque, como señaló Baldensperger, "No existe el humor, lo que hay son humoristas", afirmación ésta que tampoco resulta concluyente. Sin embargo, ateniéndome a ella, intentaré aproximarme a la parte de humorista que tuvo acusadamente la personalidad de Julio Garmendia.

Lo primero es señalar que este rasgo de su persona y de su escritura ha sido referido en varias ocasiones por quienes lo conocieron y trataron de cerca. Observemos tres o cuatro menciones a este respecto. Pedro Sotillo sostuvo en el diario El Heraldo de Caracas una columna titulada "Pastillas de lectura", la cual firmaba con el seudónimo de Fulano de Tal. A raíz del regreso de Julio Garmendia de Europa, en 1939, le dedicó una columna, en la que ya se reconocía a este escritor como "un fino humorista y excelente periodista". La misma nota añade que "la modalidad de su forma literaria gravita entre la ironía profunda y desconcertante, y un amable humorismo que llena de plácidas excelencias la prosa de sus cuentos". ${ }^{8}$ Años antes, cuando se leían en Caracas los relatos de La tienda de muñecos, un columnista cuyo nombre se desconoce, publicó en el diario Mundial de Caracas, en 1930, las siguientes certeras apreciaciones: "Cuando los autores venezolanos cultivan el humorismo lo hacen de tal modo que nunca alcanzan el equilibrio sonriente del buen humor sino la contorsionada y detonante expresión de la burla. Julio Garmendia, en cambio, es dueño de la risa mesurada, de la ironía rica y discreta". Y más recientemente, la opinión de un joven poeta y crítico venezolano, Luis Alberto Crespo, quien hace estos señalamientos: "Parejamente, el autor de La tienda de muñecos anima la anécdota concebida del modo antes señalado con el tono humorístico o la fina ironía, agregados éstos que coadyuvan a otorgar al desarrollo del asunto una doble cualidad: la de movilizar lo fantástico casi al ras de su oponente, la realidad real, responsabilizándola de ser causante de lo tragi-cómico, o la ironía propiamente dicha, cuando el personaje y su vicisitud sirven de arquetipo al hombre y a la sociedad". 9

En lo esencial, todos estos conceptos sobre el sentido del humor y de la ironía en Julio Garmendia, corroboran lo que ya habían anotado los dos célebres prologuistas de $L a$ tienda de muñecos. Jesús Semprum, en 1925, concluye así su breve juicio sobre Garmendia: "En nuestra literatura, poblada ahora de ceños encapotados, de ayes y de suspiros en el

\footnotetext{
${ }^{6}$ Esta cita de Wenceslao Fernández Flórez corresponde al prólogo de su obra Antología del humorismo, citada por Eduardo Robles Piquer (RAS) en la entrevista titutlada: "Julio Garmendia; escritor casi perdido vive en un hotel modesto de Caracas". Diario La Esfera, 29 de enero de 1962. Suplemento La Esfera en la Cultura.

${ }^{7}$ Luigi Pirandello, op. cit.

${ }^{8}$ Diario El Heraldo (Caracas, 15 de noviembre de 1939).

${ }^{9}$ Diario El Nacional (Caracas, 27 de abril de 1970).
} 
claro de luna, la sonrisa de Julio Garmendia parecerá sin duda irreverente y profana ... Esta sonrisa es testimonio de sano equilibrio. Contrasta en su esplendor ingenuo y jovial con las oscuras muecas de la sensualidad, del escepticismo y el desconsuelo: denota vida, salud y esperanza". Y Zumeta, un año después, en 1926, en la carta que le dirigió a Garmendia, le dice: "Sucede que entre lo que tenemos de distintivo los venezolanos, está el hábito de ahogar en zumba lo serio, lo tedioso. Si en París todo concluye o concluía en canción, allá todo remata en chiste o epigrama. Cultivamos sin descanso el arte sutil de embromarnos; pero, a no ser en prosa o verso festivos y fáciles, o entre dardos y aguijones nada áticos de polémica, historia y crítica, 'rotativas', ¿quién oyó nunca revolar la abeja en nuestras letras? Y ahora la sonrisa de usted viene a romper aquella flagrante y pertinaz contradicción entre lo que se escribe y lo que se habla en Venezuela, entre lo campanudo de aquello y lo chispeante y retozón de esto".

Acogiéndome a la recomendación de Pirandello, ¿cuál es la concepción del humor que proyectaba Julio Garmendia en sus cuentos? Comencemos por precisar cómo éste entendió el humorismo. Sus respuestas en otra entrevista nos interesan con respecto al tema en desarrollo.

$R A S$. ¿Nunca ha escrito novelas ni hecho otra forma de literatura que el cuento?

Julio Garmendia: El cuento, como la poesía lírica, es la forma de expresión literaria más venezolana, quizá porque es la más accesible para nuestro público. Yo nunca he tenido tentación de novelista. Mi mente tiene tendencia a la síntesis antes que al análisis, más bien a reducir que a ampliar. Me parece que el cuentista, y más si el cuento contiene cierto humorismo, equivale y tiene parentesco con el caricaturista que busca sintetizar en unas líneas todo lo que quiere decir de una persona o de unos hechos.

$R A S:$ ¿Su humorismo es intencionado?

Julio Garmendia: El humorismo es un cierto sesgo de las cosas, de gran fragilidad. No se puede "hacer humorismo" porque todo lo que es deliberado en arte o en la obra literaria resulta falso. Esa intención de "explotar su vena" ha perjudicado a muchos humoristas. Yo me limito a recoger en los cuentos el humorismo difuso que hay en la vida.

$R A S: ¿ Q u e ́$ humoristas venezolanos prefiere?

Julio Garmendia: De los que murieron, Job Pim. De los actuales, Aquiles Nazoa. Pero, a pesar de que el trópico tiene el matiz indefinido que caracteriza al humorismo, sin esos cambios violentos que obligan a alterar dramáticamente la vida en otros lugares, no existen en el trópico verdaderos humoristas. Querría que alguien me explicase la razón de ello, como también quisiera saber por qué no hay mujeres humoristas. ${ }^{10}$

En mi opinión, la clave de la concepción del humorismo en Julio Garmendia está dada en las tres expresiones subrayadas por mí: "es un cierto sesgo de las cosas", "tiene un matiz indefinible", "el humorismo difuso que hay en la vida".

En cuanto a lo primero, creo que la fórmula de oro de este humorista consiste en un discurso literario que se apoya en una inversión de los términos en los que se presente la realidad cotidiana, lo cual le permite al narrador ganar un punto de vista no convencional que provoca efectos en los que se mezclan, en dosis diferentes, el humor, la burla, la ironía. Esta inversión consiste en un modo de mirar el mundo al revés de como

${ }^{10}$ Eduardo Robles Piquer (RAS): entrevista citada. 
tradicionalmente se le ha visto o concebido. Ello da pie para un relato absolutamente insólito, que se aleja de la realidad sin dejar de referirse a ella, y que favorece notablemente las situaciones humorísticas al mismo tiempo que se presta para un cuestionamiento gracioso de lo convencional, de lo manido, de todo lo que ha llegado a ser lugar común poco feliz. Esta actitud narrativa en Julio Garmendia era ya un comienzo de lo que años más tarde llegaría a ser la literatura de lo absurdo, la cual posee sus propias leyes y su propia lógica, que no es la misma que se aplica a las convenciones sociales. El tema, por supuesto, juega un papel de mucha importancia en esta clase de relatos; de no elegirse acertadamente, el narrador se arriesga a caer en lo anodino, en lo intrascendente, sobre todo si se toma en consideración que este tipo de relatos conlleva una conclusión tácita, especie de moraleja o de enseñanza implícita en el texto del relato y consubstancial con su asunto.

Aquí pongo punto final a estas disquisiciones sobre la poética de Julio Garmendia. Puede adelantarse el criterio de que toda su obra es un equilibrio entre el realismo fantástico y el humorismo, las dos tendencias predominantes en su trabajo creador. Desde sus primicias literarias no existe la menor duda de que humorismo y fantasía se conjugaron para dar frutos admirables, que resultaban completamente novedosos en el panorama de las letras hispanoamericanas. 